\title{
Produção de porcelana de ossos e caracterização de suas propriedades técnicas
}

\section{(Production of bone porcelain and characterization of its technical properties)}

\author{
S. R. Bragança, C. P. Bergmann \\ Laboratório de Cerâmicos da Universidade Federal do Rio Grande do Sul - LACER/UFRGS \\ Av. Osvaldo Aranha, 99/705c. Porto Alegre, RS 90035-190 \\ saulorb@ufrgs.br
}

\begin{abstract}
Resumo
A porcelana de cinza de ossos é amplamente aceita e alcança alto valor de mercado, entretanto, sua produção ainda é pouco difundida, de modo que sua fabricação e pesquisa são restritas a poucos países. Sendo o Brasil grande produtor de gado, apresenta grande potencial para a reciclagem de ossos, podendo-se encontrar aplicação destes em materiais cerâmicos. Neste trabalho foi feita uma análise comparativa das características técnicas entre uma formulação de porcelana obtida com cinzas de ossos conforme a receita tradicional inglesa e uma formulação de porcelana tradicional. Os resultados mostraram que a sinterização de porcelana de cinzas de ossos requer cuidados extras em ciclos rápidos de queima quando comparada à porcelana tradicional, devido a um menor intervalo de gresificação. No entanto, a maior resistência mecânica e as qualidades estéticas, destacando-se a elevada alvura, fazem desta porcelana bastante atrativa em termos de potencial de aplicações industriais.
\end{abstract}

Palavras-chave: porcelanas, cinza de ossos, caracterização tecnológica.

\begin{abstract}
Porcelains from bone ash are widely accepted and present high market value, however, their manufacture and research are still restricted to few countries. As a great producer of cattle, Brazil presents great potential for the recycling of cattle bone into ceramic materials. In this work, it was realized a comparative investigation of technical properties of a typical porcelain composition manufactured from bone ash according to English traditional composition and a traditional porcelain. The results revealed that it is more difficult to sinter bone porcelain in fast firing cycles, once it showed shorter firing intervals compared to traditional porcelains. However, the higher mechanical strength and better aesthetic qualities, especially its whiteness, make bone porcelains very attractive materials in terms of industrial applications potential.
\end{abstract}

Keywords: porcelains, bone ash, technological characterization.

\section{INTRODUÇÃO}

A crescente atenção dada às questões de conservação ambiental que se observa nestes últimos anos trouxe grande interesse na reutilização e reciclagem de materiais. Embora possa parecer que exista uma ampla possibilidade de escolha de materiais que se poderia testar, o uso de resíduos em materiais cerâmicos é bem mais restrito do que se poderia a princípio supor. Por exemplo, o material (resíduo) a ser utilizado não pode liberar gases tóxicos durante a queima, como aconteceria com plásticos e borrachas, enquanto os metais devem estar inertizados no produto final. Tudo isto sem prejudicar as qualidades técnicas e estéticas das peças. Esta última condição é crítica para louças de mesa.

Em decorrência desta tendência de conservação ambiental, a porcelana de ossos passa a ter novo interesse. O fato de utilizar material reciclado em $50 \%$ de sua composição, como ossos calcinados, faz este produto ser, portanto, atrativo neste quesito. É bom lembrar que a calcinação e limpeza dos ossos podem gerar poluição, principalmente em termos de queima de gases combustíveis, mas certamente de menor impacto ambiental do que atividades de mineração.

Por si só as qualidades técnicas da porcelana de ossos já são suficientes, o que, aliás, explica a sua ampla aceitação no mercado. No entanto, é de se estranhar que a produção desta porcelana seja ainda pouco difundida, estando restrita a poucos países como Grã-Bretanha, Suécia e Japão [1]. Nos Estados Unidos existe também uma grande fábrica com produção de 15 a 20 mil peças por dia.

O Brasil é grande produtor de gado e, portanto, potencialmente tem uma ampla oferta de ossos. O uso deste material é restrito à produção de adubos, a uso em ração de animais, em objetos artísticos e em alguns utensílios, existindo ainda grande quantidade a ser colocada no mercado, principalmente em setores de maior valorização. 
Este trabalho propõe um estudo das propriedades técnicas e microestrutura de porcelanas de ossos, utilizandose a formulação tradicional inglesa. Assim, realizou-se a avaliação da gresificação das peças e caracterização tecnológica, análise de fases e microestrutura, cujos resultados foram comparados com uma formulação de porcelana tradicional.

As principais qualidades da porcelana de ossos são alvura, translucidez, refletividade, qualidade do vidrado e decoração, além de elevada resistência mecânica. Este conjunto de propriedades faz deste produto um dos mais atrativos e caros, distinguindo-se da louça de mesa comum, pelo termo bone porcelain [1-4].

Comparando-se com outros tipos de porcelanas, a porcelana de ossos é a que apresenta a maior tensão de ruptura à flexão e à laminação, além de maior tenacidade. Em relação à porcelana dura, a resistência mecânica chega a ser quase o dobro, para uma temperatura de queima menor em cerca de $100{ }^{\circ} \mathrm{C}[5,6]$.

A plasticidade da massa é conferida pelo caulim e pela argila plástica, embora a cinza de ossos também possa atuar positivamente, dentro de certo intervalo de composições, sobre a plasticidade. Como o percentual de argila plástica na formulação deve ser pequeno, a fim de evitar a perda de alvura, a plasticidade e a resistência a verde são baixas, de modo que mais tempo e cuidados especiais são requeridos no manuseio da peça a verde [4]. Em processos mecanizados pode ser necessário aumentar a resistência a verde [3]. Outras formulações utilizam pequeno percentual de quartzo (cerca de 6\%), aumentando a resistência à deformação piroplástica [7].

Atenção especial deve ser dada à qualidade dos ossos calcinados. O osso calcinado em temperatura mais baixa $\left(\sim 800{ }^{\circ} \mathrm{C}\right)$ contribui positivamente para a plasticidade da massa. No entanto, prejudica o empacotamento (o diâmetro médio de partícula após moagem é maior), consequentemente, ocorre o aumento da porosidade a verde e da contração de queima. Ossos calcinados a temperaturas de $\sim 1000{ }^{\circ} \mathrm{C}$ pouco contribuem à plasticidade, levam mais tempo na moagem, mas produzem granulometria mais fina [8]. A temperatura de calcinação de $1000^{\circ} \mathrm{C}$ é recomendada por diversos autores $[4,8,9]$.

A distribuição de tamanho de partícula do osso calcinado é um dos principais fatores que determina a qualidade do material produzido. Ossos calcinados comerciais fornecidos à indústria de porcelanas têm em geral distribuição de tamanho de partículas de $90 \%<$ $14 \mu \mathrm{m}[8]$.

O controle de uma boa calcinação pode ser feito pela medição da massa específica do osso moído ou, ainda, pela área superficial e tamanho de cristalito [4]. A utilização de espectroscopia de infravermelho pode ser utilizada para determinar o estado da calcinação, com maior precisão que as técnicas citadas anteriormente. Por exemplo, por meio da deteç̧ão da presença de grupos de cianeto, indica que o osso está mal calcinado, mesmo com medições de suas propriedades físicas estando aparentemente adequadas. Por conseguinte, ter-se-á também, neste caso, um curto intervalo de gresificação e elevada porosidade após queima, quando na utilização do osso [8].

Após a moagem dos ossos a úmido, ocorre a secagem. Esta pode ser via spray-drier ou por filtro-prensagem, desmonte da torta e extrusão. Nesta última rota, tem-se a remoção de boa parte dos íons com o descarte da água do filtro-prensa, o que facilita o controle reológico [10]. Por este mesmo motivo, o osso moído úmido é deixado em maturação por longo tempo [4]. As propriedades reológicas são bastante influenciadas pelo estado de maturação do osso moído [8]. Ressalva-se, porém, que por análise de difração de raios $\mathrm{X}$, somente a hidroxiapatita é detectada no osso calcinado a $1000{ }^{\circ} \mathrm{C}[10]$.

Quando a conformação é por colagem de barbotina, utiliza-se silicato de sódio como dispersante, obtendo-se melhor controle reológico do que com fosfato de sódio, tanato de sódio e suas combinações [10]. Bons resultados também são obtidos com acrilatos alcalinos, permitindo inclusive uma melhor estabilidade da barbotina do que com silicato de sódio [4].

A maior desvantagem do emprego de ossos em porcelanas é sem dúvida o curto intervalo de gresificação das peças. Em porcelanas de quartzo, a dissolução do mesmo garante a manutenção de uma viscosidade elevada com o aumento da temperatura, evitando o empenamento da peça [11]. A queima da porcelana de ossos requer parâmetros de controle de processo bastante restritos, pois a vitrificação ocorre em um intervalo estreito, cerca de 15 a $25{ }^{\circ} \mathrm{C}$. A temperatura máxima de queima é crítica, geralmente entre 1220 a $1250{ }^{\circ} \mathrm{C}$ [3].

A receita tradicional inglesa consiste de $50 \%$ de cinza de ossos, 25\% caulim e 25\% fundente (originalmente Cornish stone). Proporções de ossos calcinados acima de $50 \%$ significam maior custo, mas melhor alvura, translucidez e resistência após queima. Proporções menores que $50 \%$ prejudicam a cor e decrescem em qualidade as características citadas anteriormente. Portanto, baixas adições de ossos calcinados não justificariam o emprego dos mesmos [3].

A cinza de ossos atua principalmente como formadora de fase cristalina. O principal constituinte é a hidroxiapatita $\left(\mathrm{Ca}(\mathrm{OH})_{2} \cdot 3 \mathrm{Ca}_{3}(\mathrm{PO} 4)_{2}\right)$ que se decompõe formando cal $(\mathrm{CaO})$ e tri-cálcio fosfato- $\beta\left(\beta-\mathrm{Ca}_{3}\left(\mathrm{PO}_{4}\right)_{2}\right)$, segundo a reação:

$\mathrm{Ca}(\mathrm{OH})_{2} \cdot 3 \mathrm{Ca}_{3}\left(\mathrm{PO}_{4}\right)_{2} \rightarrow \mathrm{CaO}+\mathrm{H}_{2} \mathrm{O}+3 \beta-\mathrm{Ca}_{3}\left(\mathrm{PO}_{4}\right)_{2}$

A cal liberada reage rapidamente com a caolinita desidratada $\left(\mathrm{Al}_{2} \mathrm{O}_{3} \cdot 2 \mathrm{SiO}_{2}\right)$, formando a anortita $(\mathrm{CaO}$. $\left.\mathrm{Al}_{2} \mathrm{O}_{3} \cdot 2 \mathrm{SiO}_{2}\right)$ :

$\mathrm{CaO}+\mathrm{Al}_{2} \mathrm{O}_{3} \cdot 2 \mathrm{SiO}_{2} \rightarrow \mathrm{CaO} \cdot \mathrm{Al}_{2} \mathrm{O}_{3} \cdot 2 \mathrm{SiO}_{2}$ 
Tabela I - Fases constituintes da porcelana de ossos em diferentes temperaturas [7]. [Table I - Constituent phases of bone porcelain at different temperatures [7].]

\begin{tabular}{cl}
\hline Temperatura $\left({ }^{\circ} \mathrm{C}\right)$ & Fases Formadas \\
\hline 25 & quartzo- $\alpha$, hidroxiapatita, microclínio, nefelina, caulinita \\
600 & quartzo- $\alpha$, hidroxiapatita, microclínio, nefelina, \\
700 & quartzo- $\alpha$, hidroxiapatita, microclínio, nefelina, sanidina \\
800 & quartzo- $\alpha$, hidroxiapatita, microclínio, nefelina, sanidina, tri-cálcio fosfato- $\beta$ \\
900 & quartzo- $\alpha$, hidroxiapatita, microclínio, nefelina, sanidina, tri-cálcio fosfato- $\beta$, anortita \\
1000 & quartzo- $\alpha$, hidroxiapatita, microclínio, nefelina, tri-cálcio fosfato- $\beta$, anortita \\
1100 & quartzo- $\alpha$, hidroxiapatita, microclínio, nefelina, tri-cálcio fosfato- $\beta$, anortita \\
1200 & quartzo- $\alpha$, hidroxiapatita, tri-cálcio fosfato- $\beta$, anortita \\
1300 & quartzo- $\alpha$, tri-cálcio fosfato- $\beta$, anortita, vidro \\
1400 & quartzo- $\alpha$, tri-cálcio fosfato- $\beta$, anortita, vidro \\
1500 & Vidro \\
\hline
\end{tabular}

Utilizando uma batelada de $50 \%$ de cinza de ossos (hidroxiapatita), 30\% de caulim (caolinita), 16\% de nefelinasienito (microclínio, nefelina) e 6\% de sílica (quartzo$\alpha$ ), mantendo-se $3 \mathrm{~h}$ em cada temperatura, Iqbal et al. [7] chegaram as seguintes transformações de fases durante a queima, mostradas na Tabela I:

O desenvolvimento mostrado até aqui considera que todo o óxido fosfórico é utilizado na formação do tri-cálcio fosfato- $\beta$. Porém, uma outra rota é sugerida na qual o óxido fosfórico atua também na formação de um vidro, porém, não existe ainda um consenso na literatura, já que alguns investigadores encontraram fósforo na composição do vidro $[2,12]$ e outros não $[4,9,13]$. A reação que deixa parte do óxido fosfórico livre é a seguinte:

$3\left[\mathrm{Ca}(\mathrm{OH})_{2} \cdot 3 \mathrm{Ca}_{3}\left(\mathrm{PO}_{4}\right)_{2}\right]+6\left[\mathrm{Al}_{2} \mathrm{O}_{3} \cdot 2 \mathrm{SiO}_{2}\right] \rightarrow$
$6\left[\mathrm{CaO} \cdot \mathrm{Al}_{2} \mathrm{O}_{3} \cdot 2 \mathrm{SiO}_{2}\right]+\mathrm{P}_{2} \mathrm{O}_{5}+3 \mathrm{H}_{2} \mathrm{O}+8 \mathrm{Ca}_{3}\left(\mathrm{PO}_{4}\right)_{2}$

Como resultado destas reações, a porcelana de ossos possui cerca de $70 \%$ de fases cristalinas e $30 \%$ de vidro. Outras porcelanas apresentam o oposto: $30 \%$ de fases cristalinas e $70 \%$ de vidro. Isto explicaria a maior resistência e maior tenacidade da porcelana de ossos, enquanto a excelente compatibilidade das fases explicaria as demais propriedades anteriormente citadas.

\section{MATERIAIS E MÉTODOS}

Os ossos oriundos de abate bovino foram calcinados em forno elétrico a $1000{ }^{\circ} \mathrm{C}$, moídos a seco e peneirados, tendo sua distribuição de tamanho de partículas (granulômetro a laser, CILAS modelo 1180) apresentada na Fig. 1. Os ossos tiveram que ser preparados em laboratório, uma vez que não existem no mercado brasileiro ossos calcinados com a requerida qualidade para emprego na indústria de louças. A formulação utilizada neste trabalho foi uma típica para a

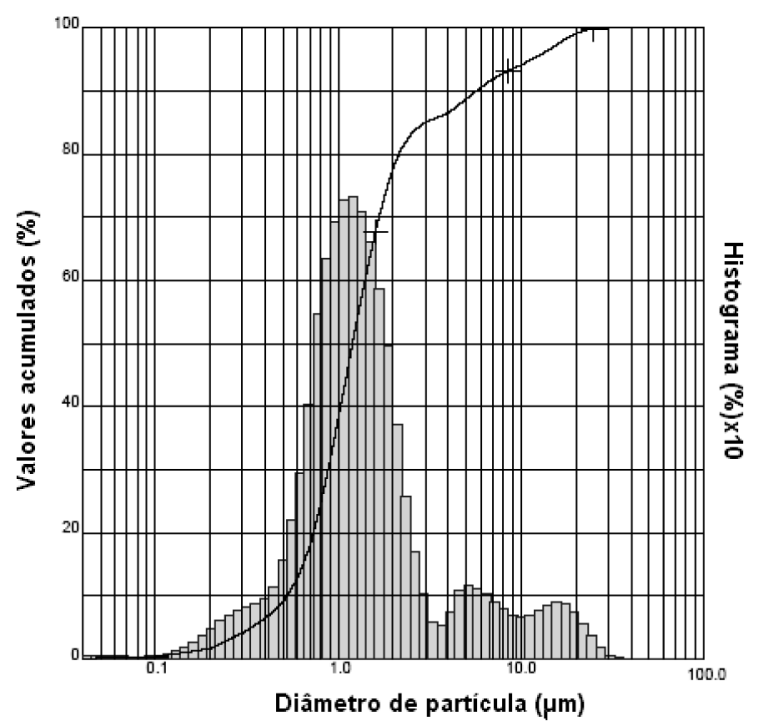

Figura 1: Distribuição de tamanho de partícula para a cinza de ossos.

[Figure 1: Particle size distribution of bone ash.]

produção de porcelana de ossos. Para efeito de comparação, foi também produzida uma porcelana triaxial tradicional, isto é, à base de argila-feldspato-quartzo. A Tabela II apresenta a composição química das matérias-primas feita por fluorescência de raios $\mathrm{X}$.

Assim, a formulação da massa de porcelana de ossos correspondeu à proporção de $50 \%$ de ossos calcinados, 25\% de caulim, e $25 \%$ de feldspato potássico. Esta proporção é básica para diversos produtos conhecidos como louças de ossos. A formulação típica de porcelana tradicional foi de $50 \%$ de caulim, $25 \%$ de quartzo e $25 \%$ de feldspato potássico.

As massas foram moídas a seco em moinho de bolas tipo “periquito”, utilizando-se todas as matérias-primas passantes 
Tabela II - Composição química das matérias-primas. [Table II - Chemical composition of raw materials.]

\begin{tabular}{ccccc}
\hline (\%) & Caulim & $\begin{array}{c}\text { Osso } \\
\text { calcinado }\end{array}$ & Quartzo & $\begin{array}{c}\text { Feldspato } \\
\text { Potássico }\end{array}$ \\
\hline $\mathrm{SiO}_{2}$ & 46,96 & 0,8 & 99,81 & 69,2 \\
$\mathrm{Al}_{2} \mathrm{O}_{3}$ & 38,05 & 1,8 & 0,12 & 16,2 \\
$\mathrm{Fe}_{2} \mathrm{O}_{3}$ & 0,46 & 0,2 & 0,08 & 0,33 \\
$\mathrm{MgO}$ & - & 1,3 & $<0,01$ & 0 \\
$\mathrm{CaO}$ & 0,02 & 50,1 & $<0,01$ & 0,65 \\
$\mathrm{Na} \mathrm{O}_{2}$ & 0,03 & 2,5 & 0,03 & 3,3 \\
$\mathrm{~K}_{2} \mathrm{O}$ & 1,14 & 1,3 & 0,06 & 9,79 \\
$\mathrm{TiO}_{2}$ & 0,03 & - & 0,073 & 0,05 \\
$\mathrm{P}_{2} \mathrm{O}_{5}$ & 0,108 & 37,2 & 0,02 & 0,5 \\
\hline $\mathrm{PF}$ & 13,20 & 4,32 & - & - \\
\hline Total & 99,9 & 99,5 & 100 & 100 \\
\hline
\end{tabular}

PF = Perda ao fogo

em peneira ABNT malha 325 (abertura de $45 \mu \mathrm{m}$ ). A seguir, a massa foi homogeneizada por 5 min no moinho periquito, umidificadas com água ( $8 \%$ em peso) e granuladas por peneiramento em malha ABNT $20(0,84 \mathrm{~mm})$. Na seqüência, as massas cerâmicas foram prensadas uniaxialmente por simples efeito em prensa hidráulica, cominuídas por gral, secas em estufa e novamente peneiradas (em malha 20), umidificadas $(8 \%$ em peso) e prensadas (a $20 \mathrm{MPa}$ ) nas dimensões $8 \times 20 \times 60 \mathrm{~mm}^{3}$. As amostras foram secas durante $48 \mathrm{~h}$ ao ar livre e ficaram em estufa a $110^{\circ} \mathrm{C}$ por no mínimo mais $24 \mathrm{~h}$. As medições de perda de peso em relação ao tempo de secagem mostraram que a partir deste tempo, não há mais perda de peso nas peças. Para comparação dos produtos, utilizou-se densidade a seco de $1,90 \mathrm{~g} / \mathrm{cm}^{3} \mathrm{em}$ média. Ressalva-se que as formulações testadas requerem cuidados extras durante a prensagem, devido ao baixo conteúdo de material argiloso.

Na investigação do comportamento da resistência mecânica da porcelana de ossos, realizaram-se testes com adição de $6 \%$ de quartzo à batelada, variando-se a granulometria desse material de duas maneiras: passante na peneira ABNT malha 200 e passante na peneira ABNT malha 325, em bateladas distintas.

Os corpos-de-prova foram queimados em forno elétrico tipo mufla. As temperaturas de queima investigadas variaram dentro do intervalo de $1180{ }^{\circ} \mathrm{C}$ a $1380^{\circ} \mathrm{C}$. A taxa de aquecimento foi de $100^{\circ} \mathrm{C} / \mathrm{h}$ e o patamar de $2 \mathrm{~h}$, para a porcelana de ossos. Para a porcelana tradicional (PT), utilizou-se taxa de $150{ }^{\circ} \mathrm{C} / \mathrm{h}$ e patamar de 30 min. O patamar de queima maior para a queima da porcelana de ossos deve-se à utilização de um material calcinado, embora ambos os ciclos para as duas porcelanas estudadas possam ser considerados ciclos rápidos. A utilização de ciclos rápidos para a queima de porcelana de ossos é inclusive prática industrial [9].

A caracterização tecnológica das porcelanas obtidas consistiu da determinação da absorção d'água (princípio de Arquimedes), retração linear (por paquímetro), a perda de peso (em balança analítica) e a tensão de ruptura à flexão por carregamento em quatro pontos [14]. Os ensaios foram praticados com um mínimo de dez corpos-de-prova, sendo utilizada a média aritmética dos valores obtidos. A microestrutura foi observada em microscópio eletrônico de varredura e as fases foram analisadas por difração de raios X.

\section{RESULTADOS E DISCUSSÃO}

A curva de gresificação das porcelanas investigadas é apresentada na Fig. 2. Com base nas curvas obtidas, pode-se observar que a porcelana de ossos apresentou gresificação em temperatura bem mais baixa. Observa-se ainda na Fig. 2 que o intervalo de queima é mais curto para a porcelana de ossos, quando comparado ao mesmo intervalo da porcelana tradicional.

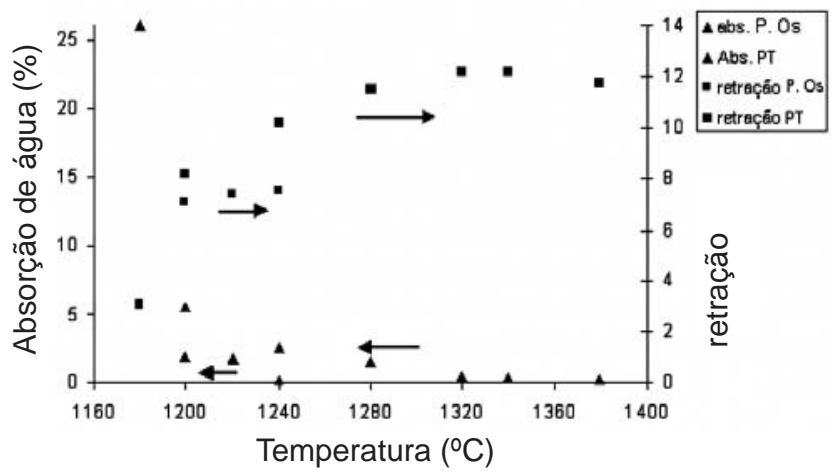

Figura 2: Curva de gresificação (absorção de água e retração linear em função da temperatura de queima). Porcelana tradicional - PT (30 min na temperatura de pico) e porcelana de ossos - P. Os (120 min na temperatura de pico).

[Figure 2: Gresification curve (absorption of water and linear shrinkage as a function of the firing temperature). Traditional porcelain - PT (30 min at peak temperature) and bone porcelain - P. Os. (120 min at peak temperature).]

De acordo com o diagrama de fases do sistema anortitatricálcio fosfato-sílica, a maturação da formulação da porcelana de ossos ocorre somente em temperaturas mais altas do que a temperatura de gresificação da porcelana de ossos [9]. Portanto, a gresificação deve ocorrer devido aos óxidos minoritários alcalinos $\mathrm{K}_{2} \mathrm{O}, \mathrm{Na}_{2} \mathrm{O}$, sofrendo forte influência do $\mathrm{CaO}$, liberado da decomposição da hidroxiapatita. A presença de $\mathrm{CaO}$, portanto, constitui-se em uma diferença em relação à porcelana tradicional. $\mathrm{O}$ óxido de cálcio pode formar eutético para o diagrama $\mathrm{CaO}$ $\mathrm{SiO}_{2}-\mathrm{Al}_{2} \mathrm{O}_{3}$, mas ainda mais significativo, são os eutéticos em digramas quaternários envolvendo os óxidos alcalinos [15]. Isso foi confirmado, pela análise com microssonda EDS, que detectou Ca na fase vítrea, além de $\mathrm{Al}, \mathrm{Si}, \mathrm{O}, \mathrm{K}$, 
Na e P em [9]. Iqbal et al. mostram ainda que a proporção de $\mathrm{CaO}$ no vidro varia conforme a microrregião analisada, podendo chegar a $20 \%$ em peso do total [9]. Existe também a possibilidade da vitrificação ser auxiliada por compostos transientes de baixo ponto de fusão de fosfatos, mesmo que o fósforo não permaneça na fase vítrea final $[4,9]$.

No presente trabalho, em análise por microssonda EDS, encontrou-se a presença de fósforo na fase vítrea. Há a possibilidade de interferência de cristais de tri-cálcio fosfato, uma vez que os mesmos podem se apresentar bastante dispersos e em tamanhos submicrométricos, o que poderia explicar resultados aparentemente contraditórios na literatura quanto à presença do fósforo na fase vítrea [2, $4,9,12]$. Por outro lado, notou-se nos referidos trabalhos, que o fósforo foi detectado na composição da fase vítrea somente quando havia sódio na mesma. Isto levou os autores à hipótese de que a estabilidade de um vidro de fosfato na porcelana pode ser influenciada pela presença de sódio. Esta hipótese encontrou-se fundamentada na literatura sobre vidros [16]. Salienta-se ainda que o fósforo deve contribuir na vitrificação desta porcelana, direta ou indiretamente.

É interessante notar que mesmo para uma quantidade significativamente menor de fase vítrea, a porcelana de ossos atinge baixo percentual de absorção de água, chegando a valores menores que $0,5 \%$ para a temperatura de $1240{ }^{\circ} \mathrm{C}$. Os dados técnicos são apresentados na Tabela III.

Os resultados experimentais confirmaram que a porcelana de ossos apresenta elevada resistência mecânica, medida pela tensão de ruptura à flexão (TRF). Considerando que ambas as formulações foram testadas em condições experimentais bastante próximas, é notória a maior resistência mecânica da porcelana de ossos, que alcançou $71 \mathrm{MPa}\left(\mathrm{em} 1240{ }^{\circ} \mathrm{C}\right.$ ), enquanto a porcelana tradicional chegou a $46 \mathrm{MPa}\left(\mathrm{em} 1380{ }^{\circ} \mathrm{C}\right)$.

A resistência mecânica da porcelana tradicional é fortemente dependente do teor de quartzo e, principalmente, do diâmetro das partículas desta matéria-prima, sendo isto objeto de análise em diversos estudos [17, 18]. Em outros trabalhos dos autores, este assunto também já foi investigado, mostrando que a resistência mecânica da porcelana tradicional é limitada pela interconexão de trincas na matriz geradas devido à tensão residual no quartzo, sendo isto demonstrado em micrografias [19, 20]. Otimizando-se o tamanho de partícula de quartzo, para valores entre 15-30 $\mu \mathrm{m}$ é possível se maximizar a resistência mecânica da porcelana tradicional, mas dificilmente encontram-se valores TRF superiores a 60 MPa, uma vez que a mesma passa a ser limitada pela própria resistência do grão de quartzo, como demonstrou o trabalho de Carty [18]. Uma porcelana comercial não precisa de valores tão elevados de resistência mecânica, embora existam estudos que apresentam formulações de porcelanas de ossos com valores de TRF superiores a 90 $\mathrm{MPa}$ [1] e porcelanas tradicionais de $80 \mathrm{MPa}$ [21].

Quanto ao efeito da presença de quartzo sobre a resistência mecânica, na formulação da porcelana de ossos, os resultados mostraram uma redução do valor de TRF para valores similares ao da porcelana tradicional (48 MPa), utilizando partículas de quartzo passantes na peneira ABNT de malha 325. Utilizando-se quartzo de maiores tamanhos de partículas (passante na peneira de abertura de malha 200) a TRF decresce bastante, chegando a valores inferiores a $35 \mathrm{MPa}$. Portanto, o beneficiamento das matérias-primas como caulim e feldspato, retirando o quartzo grosseiro quando houver, também é crítico para a porcelana de ossos. Isto ficou evidente pela baixa

Tabela III - Absorção de água, massa específica bulk (m.e.b.) e tensão de ruptura por flexão (TRF) das porcelanas tradicional e de ossos, em função da temperatura de queima.

[Table III - Absorption of water, bulk density and flexural strength of traditional and bone porcelain, as a function of firing temperature.]

\begin{tabular}{ccccccc}
\hline $\begin{array}{c}\text { Temperatura } \\
\left({ }^{\circ} \mathrm{C}\right)\end{array}$ & $\begin{array}{c}\text { Porcelana tradicional } \\
\text { abs. de água } \\
(\%)\end{array}$ & $\begin{array}{c}\text { m.e.b. } \\
\left(\mathrm{g} / \mathrm{cm}^{3}\right)\end{array}$ & $\begin{array}{c}\text { TRF } \\
(\mathrm{MPa})\end{array}$ & $\begin{array}{c}\text { Abs. de água } \\
(\%)\end{array}$ & $\begin{array}{c}\text { m.e.b. } \\
\left(\mathrm{g} / \mathrm{cm}^{3}\right)\end{array}$ & $\begin{array}{c}\text { TRF } \\
(\mathrm{MPa})\end{array}$ \\
\hline 1180 & - & - & - & 25,97 & 2,09 & 25 \\
1200 & 5,52 & 2,09 & 24 & 1,81 & 2,30 & 51 \\
1220 & - & - & - & 1,71 & 2,32 & 59 \\
1240 & 2,55 & 2,16 & 28 & 0,12 & 2,36 & 71 \\
1260 & - & - & - & Sobrequeima & - & - \\
1280 & 1,53 & 2,21 & 36 & - & - & - \\
1320 & 0,46 & 2,25 & 38 & - & - & - \\
1340 & 0,34 & 2,32 & 46 & - & - & - \\
1380 & 0,22 & 2,27 & 41 & - & - & - \\
\hline
\end{tabular}




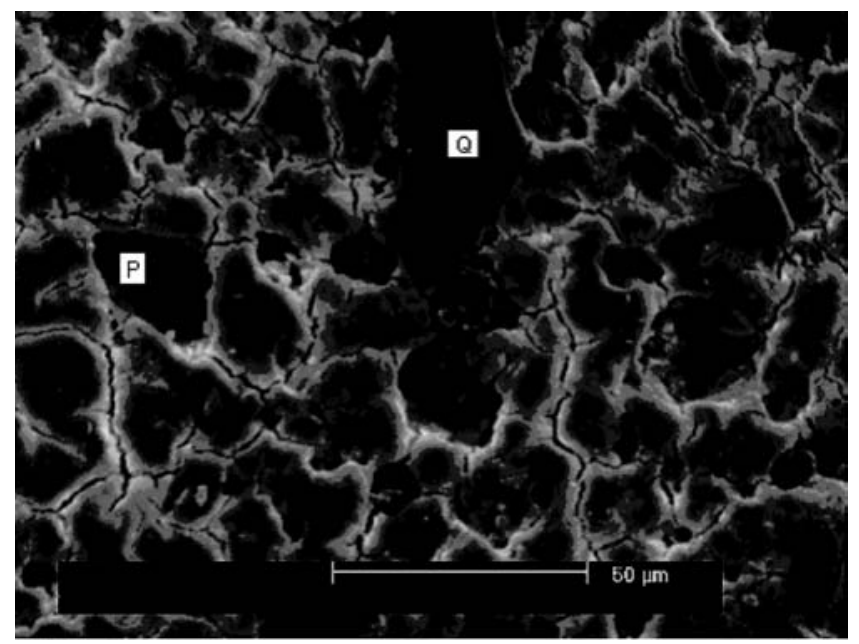

Figura 3: MEV da porcelana de ossos queimada a $1200{ }^{\circ} \mathrm{C}$. Seção transversal. Q: quartzo. P: poro. Ataque ácido HF 10\%, $20 \mathrm{s.}$

[Figure 3: SEM of bone porcelain fired at $1200{ }^{\circ} \mathrm{C}$. Transversal section. Q: quartz. P: pore. Acid etching HF 10\%, 20 s.]

dissolução do quartzo na fase vítrea, permanecendo com elevado tamanho de partícula. A Fig. 3 apresenta a micrografia após ataque ácido (ácido fluorídrico por 20 s) de uma porcelana de ossos, queimada a $1200{ }^{\circ} \mathrm{C}$. Nesta micrografia, além do grão de quartzo $(\mathrm{Q})$, tem-se um poro (P) devido provavelmente à remoção de grão durante a preparação ceramográfica da amostra. A matriz consiste de tricálcio fosfato e anortita.

Nota-se ainda a textura bastante fraturada característica dessa formulação, similar ao aspecto de fratura de matriz apresentado no trabalho de Iqbal et al. [7]. A matriz fratura supostamente devido à diferença de expansão térmica entre ela e os clusters de grãos de tri-cálcio fosfato- $\beta$.

A Fig. 4 apresenta a micrografia da mesma porcelana

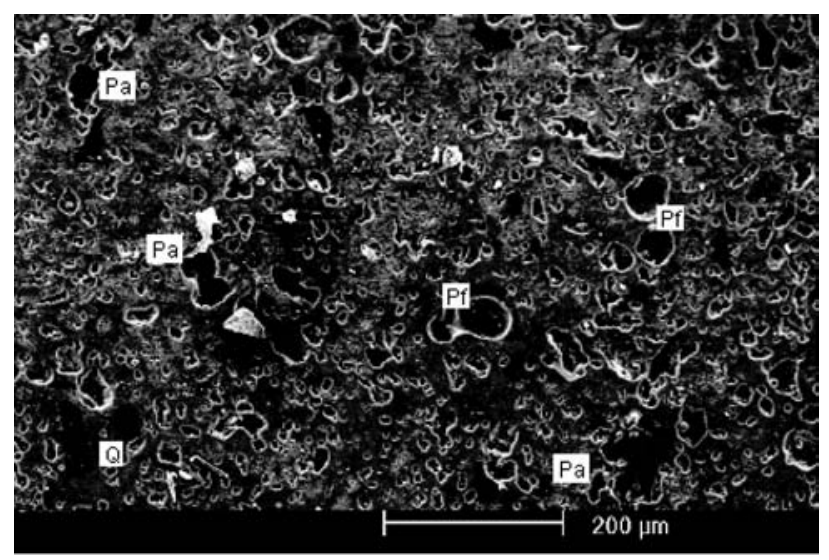

Figura 4: MEV da porcelana de ossos queimada a $1200^{\circ} \mathrm{C}$. Seção transversal. Q: quartzo. Pf: poro fechado. Pa: poro aberto. Sem ataque ácido.

[Figure 4: SEM of bone porcelain fired at $1200^{\circ} \mathrm{C}$. Transversal section. Q: quartz. Pf: closed pore. Pa: open pore. No acid etching.]

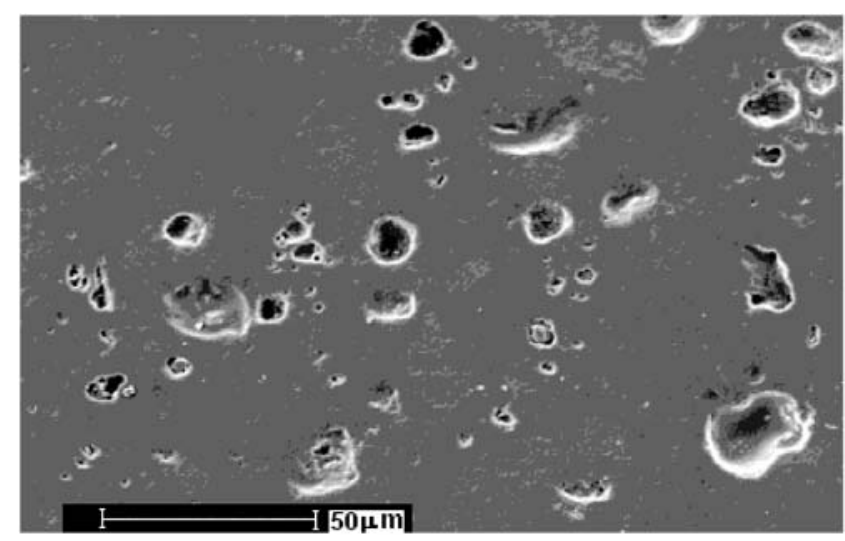

Figura 5: MEV da porcelana de ossos queimada a $1240{ }^{\circ} \mathrm{C}$. Seção transversal. Porosidade fechada. Sem ataque ácido.

[Figure 5: SEM of bone porcelain fired at $1240{ }^{\circ} \mathrm{C}$. Transversal section. Closed porosity. No acid etching.]

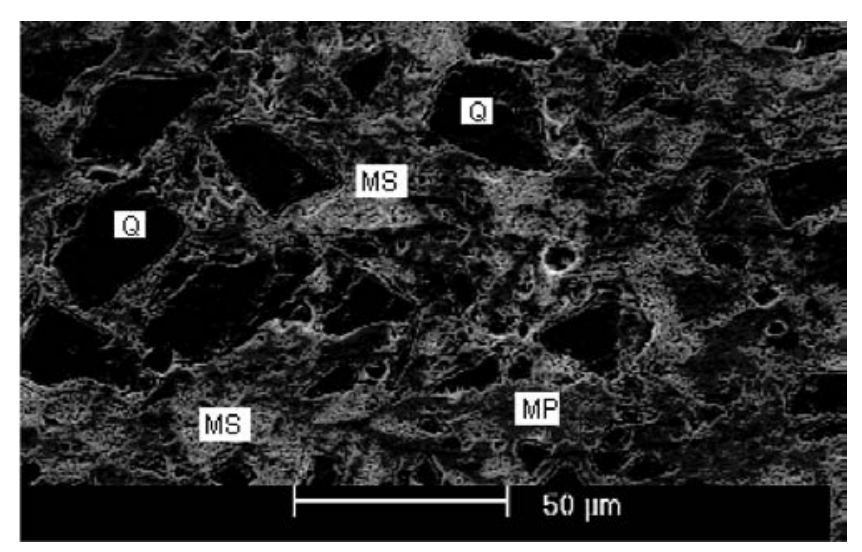

Figura 6: MEV da porcelana tradicional. Superfície da amostra queimada a $1340{ }^{\circ} \mathrm{C}$ e atacada com $\mathrm{HF}$ a $20 \%$ por 10 s. Q: quartzo; MP: mulita primária e MS: mulita secundária.

[Figure 6: SEM of traditional porcelain. Sample surface fired at $1340{ }^{\circ} \mathrm{C}$ and etched in HF 20\% for 10 s. Q: quartz; MP: primary mullite and MS: secondary mullite.]

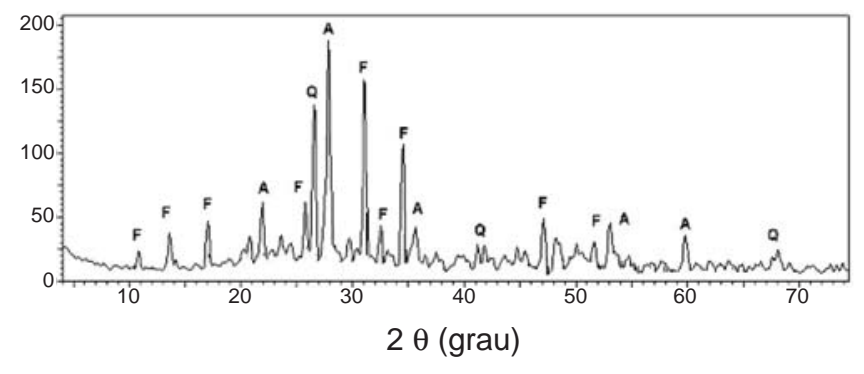

Figura 7: Análise de fases por difração de raios X. Anortita (A), tri-cálcio fosfato (F) e quartzo (Q).

[Figure 7: Phase analysis by X-ray diffraction. Anorthite (A), tricalcium phosphate $(F)$ and quartz $(Q)$.]

da Fig. 3, porém sem ataque ácido. Deste modo, pode ser observada a fase vítrea cobrindo quase toda superfície 


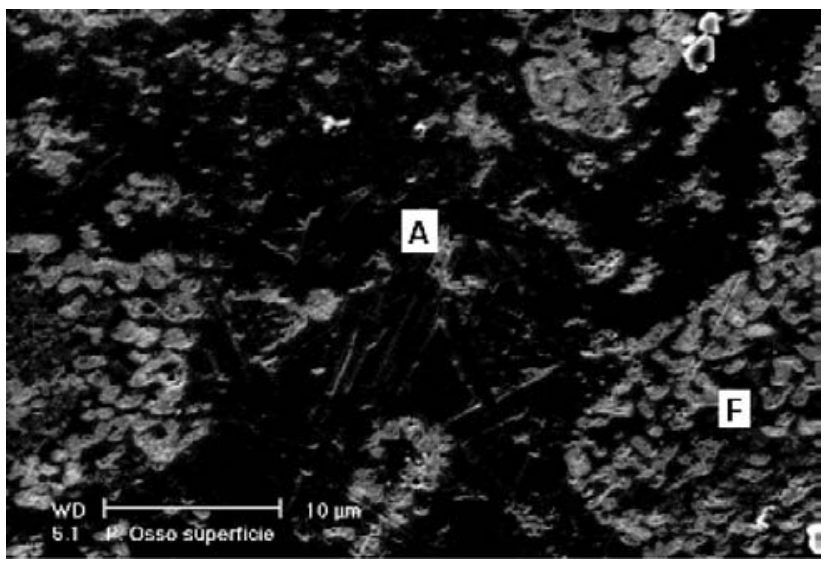

Figura 8: MEV da porcelana de ossos. Superfície da amostra queimada a $1240{ }^{\circ} \mathrm{C}$. A: anortita. F: tri-cálcio fosfato. Ataque ácido HF 10\%, $10 \mathrm{~s}$.

[Figure 8: SEM of bone porcelain. Surface of the sample fired at $1240{ }^{\circ} \mathrm{C}$. A: anorthite. F: tri-calcium phosphate. Acid etching $\mathrm{HF}$ $10 \%, 10 \mathrm{~s}$.

da amostra. Nota-se a presença de poros fechados e arredondados, partículas de quartzo e porosidade aberta, a qual justifica os parâmetros técnicos encontrados na Tabela III. Em temperaturas mais elevadas $\left(1240{ }^{\circ} \mathrm{C}\right)$, não foi observada porosidade aberta, sendo a fase vítrea suficiente para cobrir toda amostra, justificando a baixa absorção de água $(<0,5 \%)$, similar às porcelanas comuns (Fig. 5).

A Fig. 6 permite ainda mais evidenciar a diferença de microestrutura entre a porcelana de ossos e a porcelana tradicional. Esta apresenta como principais fases o quartzo e a mulita (primária e secundária). A ausência de mulita na porcelana de ossos é explicada pela reação mais favorável e rápida do $\mathrm{CaO}$ com o metacaulim, formando anortita [4].

A análise cristalográfica de fases da porcelana de ossos é apresentada na Fig. 7, indicando a presença de anortita, tri-cálcio fosfato e quartzo. Está análise confirma a reação de todas as matérias-primas sem a presença de partículas remanescentes (relictos) de feldspatos ou hidroxiapatita. A Fig. 8 mostra anortita, além de tri-cálcio fosfato- $\beta$, na microestrutura da porcelana de ossos queimada a $1240{ }^{\circ} \mathrm{C}$, após ataque ácido HF 10\%, 10 s. As fases formadas na porcelana de ossos são bem diferenciadas da porcelana tradicional, principalmente pela ausência de mulita.

\section{CONCLUSÕES}

O óxido de cálcio liberado da decomposição da hidroxiapatita é responsável pela menor temperatura de queima da formulação de porcelana de ossos em relação à formulação de porcelana tradicional. A porcelana de ossos apresentou menor intervalo de queima em relação à porcelana tradicional, sendo esta a maior desvantagem desta formulação.
A presença de fósforo foi encontrada na composição final da fase vítrea final. A estabilidade de um vidro de fosfato na porcelana pode ser possível pela presença de sódio na fase vítrea.

A resistência mecânica é notadamente maior para a porcelana de ossos. No entanto, a presença de quartzo grosseiro (diâmetro máximo de partícula de $<45 \mu \mathrm{m}$ ) em uma formulação de porcelana de ossos, mostrou-se bastante prejudicial à resistência mecânica, cujos valores passaram a ser similares aos da porcelana tradicional.

As fases formadas na porcelana de ossos são bem diferenciadas da porcelana tradicional, principalmente pela presença de anortita e tri-cálcio fosfato- $\beta$ e ausência de mulita.

\section{AGRADECIMENTOS}

Os autores agradecem ao $\mathrm{CNPq}$ pelo apoio financeiro.

\section{REFERÊNCIAS}

[1] C. G. Portillo, Bol. Soc. Céram. Vidrio 38, 5 (1998) 397-402.

[2] A. Kara, R. Stevens, J. Eur. Ceram. Soc. 22, 5 (2002) 731-736.

[3] C. E. L. Franklin, A. J. Forrester, Trans. J. Br. Ceram. Soc. 74, 4 (1975) 141-145.

[4] P. Rado, Bone china, Ceramics Monographs - A Handbook of Ceramics, Verlag Schmidt GmbH Freiburg i. Brg. (1981).

[5] S. A. F. Batista, P. F. Messer, R. J. Hand, Br. Ceram. Trans. 100, 6 (2001) 256-258.

[6] P. Rado, Trans. J. Brit. Cer. Soc. 70 (1971) 131-139.

[7] Y. Iqbal, P. F. Messer, W. E. Lee, Br. Ceram. Trans. 99, 5 (2000) 193-199.

[8] J. J. Cooper, Br. Ceram. Trans. 94, 4 (1995) 165168.

[9] Y. Iqbal, P. F. Messer, W. E. Lee, Br. Ceram. Trans. 99, 3 (2000) 110-116.

[10] D. Basnett, P. J. Cartwrigtht, Trans. J. Br. Ceram. Soc. 88, 5 (1989) 191-195.

[11] K. H. Schüller, Porcelain, Ceramics Monographs - A Handbook of Ceramics, Verlag Schmidt GmbH Freiburgi. Brg. (1979).

[12] A. Kara, R. Stevens, J. Eur. Ceram. Soc. 22, 5 (2002) 737-743.

[13] P. D. S. St. Pierre, J. Am. Ceram. Soc. 38, 6 (1955) 217-222.

[14] ASTM C - 133/94; ASTM C - 133/97. ASTM American Standards for Testing Materials.

[15] J. F. Shairer, J. Am. Cer. Soc. 40, 7 (1957) 215235.

[16] J. M. F. Navarro, El Vidrio, CSIC, Madrid (1991) 99. 
[17] S. I. Warshaw, R. J. Seider, J. Am. Ceram. Soc. 50 (1967) 337-342.

[18] W. M. Carty, B. M. Pinto, Ceram. Eng. Sci. Proc. 23, 2 (2002).

[19] S. R. Bragança, C. P. Bergmann, Ceram. Int. 29 (2003) 801-806.
[20] S. R. Bragança, C. P. Bergmann, H. Hübner, J. Eur. Ceram. Soc., in press, www.sciencedirect.com (2006).

[21] O. I. Ece, Z. Nakagawa, Ceram. Int. 28 (2002) 131140.

(Rec. 01/02/2005, Rev. 04/10/2005, 13/03/2006, Ac. 23/03/2006) 